\title{
The Effect of Socio-Demographic Factors on Risky-Sexual Behaviours of Adolescents in the North West Province of South Africa
}

\author{
Acheampong Yaw Amoateng, Ishmael Kalule-Sabiti and Yaw Johnson Arkaah \\ School of Research and Post-Graduate Studies \\ North-West University (Mafikeng Campus), South Africa.
}

\begin{abstract}
The present study sought to fill a research void on adolescent problem behaviours in South Africa by examining individual and contextual factors that affect sexual-risk taking behaviours amongst black African adolescents in a poor community of the North West Province of South Africa. Using the logistic and Poisson regression analytical techniques, we find that individual and contextual factors such as gender, grade, religiosity, peer influence, parental value of children, parent-child communication, school attachment, the use of alcohol and substance like tobacco and marijuana all affect sexual risk behaviours like lifetime sex, recent sexual activity and involvement with multiple sexual partners. Policy implications of these findings are discussed.
\end{abstract}

Keywords: Substance use; Peer influence; lifetime sex; religiosity; School attachment

\section{Résumé}

La présente étude a cherché à combler un vide recherche sur les adolescents comportements à problème en Afrique du Sud par l'examen individuel et facteurs contextuels qui affectent sexuelle risque de comportements chez les noirs africains des adolescents dans une communauté pauvre de la Province du nord-ouest de l'Afrique du Sud. L'aide logistique et de régression Poisson techniques analytiques, Nous constatons que les individus et facteurs contextuels tels que le sexe, le grade, la religiosité, l'influence des pairs, parental valeur des enfants, communication parent-enfant, l'école pièce jointe, l'utilisation d'alcool et de substances comme le tabac et la marijuana affecte tous les comportements sexuels à risques les comportements, comme le sexe vie récente, activité sexuelle et de la participation de multiples partenaires sexuels. Incidences sur les politiques de ces conclusions sont examinées.

Mots clé: Usage de substances; Influence des pairs; Vie sexe; Religiosité; L'école pièce jointe

\section{Introduction}

In recent years considerable attention has focused on adolescent sexual behaviour in general, especially, in sub-Saharan Africa, and how risky behaviours contribute to poor sexual health outcomes. Sub-Saharan Africa continues to record the greatest number of HIV infections and deaths worldwide, especially, amongst the youth who represent one of the fastest-growing risk groups for sexually-transmitted diseases such as HIV/AIDS. Many studies have shown that not only do South African adolescents use substances such as alcohol, tobacco and other drugs, but they also engage in high levels of sexual activity and unprotected sex (see e.g. Flisher, Reddy, Muller and Lombard 2003; Kaaya et al. 2002; Panday, Reddy and Bergstrom
2007). In their study, Shisana and Simbayi (2003) identified a similar trend towards earlier sexual debut amongst younger respondents, where the median age at first sex for respondents aged 15-24 year was found to be 16 years. Shisana and Simbayi (2003) noted, in particular, that sexually active boys uniformly typically engage in sexual activity at a much earlier age than their female counterparts.

It is against this backdrop of risky sexual behaviours amongst South Africa's youth and concerns about the health outcomes of such behaviours that we undertake the present study. The aim of the study is to examine the impact of selected socio-demographic factors on adolescent risky sexual behaviours. Specifically, the study examines the effects of such factors as grade level, age, religion, family structure, living arrangements, 
household income, peer influence, alcohol and drug use on lifetime sexual activity, recent sexual activity and lifetime sexual partners.

\section{Literature Review:}

Several studies have investigated the impact of gender on sexual behaviour and the consensus seems to be that gender does affect adolescent sexual behaviour. For example, studies have revealed that at older ages, that is, between 16 to 17 years, boys and girls are equally likely to engage in sex, even though boys are more likely than girls to have sex at an early age (Gillmore 2002; Upchurch et al. 1999, Nahom et al. 200I). In a study by the National Department of Health, it was found that six percent of young women ( 15 - 24 years) reported having had sex by the age of 15 , compared with 12 percent of young men. And, by the end of their childhood (18 years), $42 \%$ of women and $63 \%$ of men had become sexually active (Department of Health 2007). In a study of adolescents' sexual behaviour in the North West Province, Amoateng and Kalule-Sabiti (2013) found that $44 \%$ of the adolescents in the sample were sexually experienced, and of those $61 \%$ were male while $39 \%$ were female. Moreover, they found that males initiated sexual intercourse earlier than their female their counterparts; the rate for males was about $19 \%$ higher than that of females.

A number of studies have observed a positive association between age and sexual experience, that is, as age increases the participation in sexual activity also increases (e.g. Nikula 2009), although older adolescents have better knowledge and experience and are more likely to use condom/contraceptive consistently at their first sexual encounter than younger adolescents (Khan 2002). Amoateng and Kalule-Sabiti (2013), in their study of the timing of first sexual debut in a sample of adolescents, found that the rate for older adolescents was about $27 \%$ higher than the rate for younger adolescents.

Many studies have shown that people who live in urban areas have more knowledge about HIV/AIDS prevention, more likely to practice condom use than rural residents, while the chances of having more than one regular sexual partner and sexually transmitted diseases are higher in urban than in rural areas (Ntozi et al. 2000; Peltzer 2003). Karim et al. (2003) found that residence in a rural setting was associated with an increased probability of having had sex among males, while females residing in small towns were significantly more likely than their counterparts residing in cities or large towns to have had multiple recent partners. But, in a study by Kwankye (2005), he found that the proportion of participants that was sexually active was higher in the rural area than the urban district and also increased with age.

Living arrangements of adolescents have been found to impact their sexual behaviour. For example, Kirby (1999) found that living in a nontraditional family structure (i.e. families with parents who are divorced, separated, or were never married) serves as a risk factor for initiation of sex. In another study of the timing of first sexual intercourse by Upchurch et al. (1999), they found that adolescents living in a traditional family structure (i.e. families with both biological parents) reported later median age of first intercourse than youth living in any other family situation, including stepfamilies with two parents in the home. In a South African study, McGrath et al. (2009) found that the hazard of first sex was statistically significantly higher for women and men whose mother or father had died, while on the other hand they found that the hazard of first sex was statistically significantly lower for women whose mother or father was a co-member of the same household.

Widespread poverty tends to weaken moral values that moderate sexual behaviour, especially among adolescents. In particular, female adolescents tend to contend with the allurement of financial gratification and sexual overtures by relatively richer peers and adults (Isiugo-Abanihe 1993). Thus, household income is a factor that affects adolescent sexual behaviour. In their studies, Whitaker et al (2000) and Kinsman et al. (1998) found no significant relationship between adolescent sexual activity and parents' per capita income, while Lammers et al. (2000) found that higher socioeconomic status negatively correlated with sexual activity across all age groups and genders

In the United States, there appears to be consensus in the literature that substance use and sexual intercourse tend to co-occur among U.S. adolescents and among the sexual risk behaviours. Moreover, substance use is linked to higher numbers of sexual partners and less consistent condom use (e.g. Lowry, Holtzman, Truman, et al. 1994; Tapert, Aarons, Sedlar et al. 200I). In South Africa, Flisher et al. (1996) found that having ever had sex was associated with use of various 
substances, however, substance use was not associated with the failure to use a condom (Flisher and Chalton 200I).

Also, in South Africa, Simbayi, Mwaba, and Kalichman (2006) have observed that alcohol intake among South African adolescents is a major cause of concern and has been linked to other risk behaviours including unsafe sex, teenage pregnancy, dropping out of school and delinquent or criminal behaviour. In a study of Eighth Grade pupils in South Africa, Palen et al. (2006) found that during their most recent sexual encounter, $39 \%$ of the adolescents reported using alcohol or marijuana. Among those who used these substances, $23 \%$ reported that substances influenced their decision to have sex, and $26 \%$ reported using substances in order to feel more comfortable with their partner; youth who had ever used alcohol or marijuana in their lifetime were significantly more likely to have ever had sexual intercourse.

Several studies have documented the association between religion and behaviour in general and antisocial behaviour, in particular (see e.g. Garner 2000; Odimegwu 2005). As far as sexual behaviour is concerned, Garner (2000) and Odimegwu (2005) have both observed a relationship between religion and sexual attitudes. Mcmillen etal. (201 I:196) found that "the religious group to which people identify appears to be substantially correlated with how they evaluate the appropriateness of premarital sexual behaviour and with the sexual mores they choose to follow in their own lives including first sexual intercourse and less permissive attitudes about premarital sex". Several scholars have observed that adolescents who attached importance to religion were significantly more aware of the dangers of HIV/AIDS than their non-religious counterparts, they are more likely to delay sexual involvement than those with lower levels of religiosity (e.g. Hardy and Raffaelli 2003; Shisana and Simbayi 2003; Rostosky et al. 2003).

\section{Data and Methods}

The data for the study came from a survey of 1065 school-going adolescents in grades 9 and $\mathrm{II}$ in the Ngaka Modiri Molema District of the North West Province of South Africa. The sampling frame consisted of all pupils in Middle and High Schools aged between 12 and 21 years across 11 schools in the district. It involved a three-stage cluster sampling which selected the APOs, the schools and the pupils. The first stage of the sampling involved selecting 489 three Primary Sampling Units PSUs) from the five APOs available for each of the two streams, i.e. Grade 9 and Grade II.

The second stage involved selecting $4 \%$ of the schools from each of the two streams ( 127 and 98 Grade 9 and Grade II schools respectively). The third stage involved randomly selecting pupils from each of the two grades using Probability Proportional to Size (PPS) sampling technique. Finally, a simple random sampling was used to select the Grade 9 and Grade II classes in each selected school for participation in the study. Data collection at the six selected schools took place between 14th May and 20th May 2009. Information collected by the survey included adolescent's lifetime sex, sexual activity in the three months preceding the survey, use of condoms, involvement with multiple sexual partners, and age at first sexual intercourse. Amongst the individual and contextual factors examined in the survey are age, gender, religion, residence, living arrangements, household income, parent-child relationship, peer influence, school, use of alcohol, tobacco and other drugs.

\section{Measures of Variables \\ Dependent Variable}

The dependent variable in the analysis is "Adolescent Sexually Risky Behaviour". Three dimensions of adolescent sexually risky behaviour are measured in the present study. These are lifetime sex measured by asking respondents whether or not they have ever had sex? The response categories are I ='Yes' $2=$ ='No'.

The second dimension is sexual activity during the three months preceding the survey and measured by asking respondents about whether or not they had any sexual encounter during the three months preceding the survey? The responses are I ='Yes' 2='No'. The third dimension of adolescent sexually risky behaviour is involvement with multiple sexual partners. This is measured by asking respondents to indicate the number of sexual partners they have ever had. The responses range from $0=$ 'None' I='l' 2='More than one'.

\section{Individual and Contextual Variables}

Table I shows the measurement of the individual background socio-demographic factors in the analysis. The contextual factors in the analysis are measured as follows:

Parent/guardian-child communication is measured by $\mathrm{II}$ items on a 5-point Likert scale 
ranging from 1 '=strongly disagree, ' 2 '=disagree, ' 3 '=neutral, ' 4 ' $=$ agree and ' 5 ' $=$ strongly agree. Sample items include: "I freely communicate with my parents/ guardians on issues related to dating, sex and drugs at home"; "I am sometimes afraid to ask my parents/guardians for what I need.....". The responses are dichotomized into $I=$ 'Difficult' 2 ='Smooth'.

Parental Values for Children is measured by 6 items measured on a 4-point Likert scale ranging from 'I'= very important, ' 2 '=somehow important, ' 3 '= not really important, and ' 4 ' $=$ not at all important. Sample items include: "How important is it for your parents that you finish high school?"; How important is it for your parents that you get good grades?" For purposes of the logistic regression analysis, the responses are dichotomized into I=' Low' 2='High'

Religiosity is measured by five (5) items on a 5 point Likert scale with responses ranging from ' 1 '=strongly disagree, ' 2 '=disagree, ' 3 '= neutral , ' 4 ' $=$ agree and ' 5 ' $=$ strongly agree. Sample items include: "My religion is very important in my life"; "I have connections to friends and other people whom I consider religious/spiritual". For purposes of the logistic analysis, the responses are dichotomized into I ='Weak' 2='Strong'.

Sexual Media Content Exposure is measured by eleven (II) questions that relate to this, including the number of hours spent in a day watching television and access to magazines with explicit contents and renting of adult movies. Sample items include: "I take delight in watching adult/sexual programmes on TV"; "I often borrow pornographic movies from movie outlets or spend money buying magazines with adult/sexual contents Responses range from I =' High/Very high' 2=' Average' 4=' Low/Very low'. The responses are dichotomized into I = 'Much exposure' 2 ='Little exposure'

Perceptions about Sex-Related Issues is measured by six items on a 5-point Likert-scale ranging from ' $\mathrm{l}$ '=strongly disagree, ' 2 ' = disagree, ' 3 ' = neutral, ' 4 ' =agree and ' 5 ' $=$ strongly agree. Sample items include: "Watching sex on TV predicts and may hasten adolescent sexual initiation"; "Parents must discuss their own beliefs about sex and the behaviours portrayed with their children".
These are dichotomized into I='Unrealistic $2=$ 'Realistic' perceptions.

Alcohol use, Cigarette use and marijuana use are measured by single items: Have you ever drunk Alcohol/Cigarette/Marijuana? And the responses are a dichotomy of I ='Yes' 2='No.

School Attachment is measured by six items on a 3-point scale with responses ranging from "High/ Very high" to "low/Very low". Sample items include: "I enjoy going to school"; "Teachers in my school encourage me to do the best I can," However, for the logistic regression analysis, the responses were dichotomized into I =' Weak' 2='Strong'.

Peer Influence is measured by four items with a dichotomous response of I='Yes' 2='No'. Sample items include: "Have you ever been influenced by peers to have a boyfriend/ girlfriend?"; Do your friends sometimes encourage you have sex?" For purposes of the logistic regression, the responses were dichotomized into I =' Strong' 2='Weak'.

Involvement with girlfriend/boyfriend is measured by asking the respondents to indicate whether or not they have a regular partner (boyfriend/girlfriend). The responses are I-'Yes' $2=$ 'No'.

We examine the effects on the three dimensions of risky sexual behaviours of such individual and contextual factors as age, grade level, gender, residence, family background, parental supervision and monitoring, peers, religiosity, substance use.

\section{Results}

Table I shows the descriptive statistics for selected background factors. Fifty-three percent of the adolescents are female compared to $47 \%$ of males. Sixty percent of the respondents are in Grade II, while $40 \%$ are in Grade 9. There are more young adolescents $(70 \%)$ as compared to older adolescents $(27 \%)$ and young adults (3\%), while there are more urban residents than rural residents (55\% and $45 \%$ respectively). As far as parental educational attainment goes, $43 \%$ of the parents of adolescents have secondary education, followed $25 \%$ with either college or undergraduate qualifications, while $18 \%$ of parents have postgraduate qualifications; $15 \%$ have either primary education or no schooling. 
TABLE I: $\quad$ DISTRIBUTION OF SAMPLE CHARACTERISTICS

\begin{tabular}{|c|c|c|c|}
\hline BACKGROUND & CHARACTERISTICS & PER CENT & COUNT \\
\hline \multirow{2}{*}{ Gender } & Male & 47.0 & 493 \\
\hline & Female & 53.0 & 556 \\
\hline \multirow{2}{*}{ Grade } & Nine & 40.5 & 426 \\
\hline & Eleven & 59.5 & 625 \\
\hline \multirow{3}{*}{ Age Group } & $14-17$ & 70.1 & 668 \\
\hline & $18-20$ & 27.0 & 257 \\
\hline & $21-24$ & 2.9 & 28 \\
\hline \multirow{2}{*}{ Place of Residence } & Rural & 45.1 & 454 \\
\hline & Urban & 54.9 & 553 \\
\hline \multirow{4}{*}{ Parent/Guardian Education } & Primary or None & 14.5 & 145 \\
\hline & Secondary & 42.5 & 425 \\
\hline & Undergrad Univ/College & 25.2 & 252 \\
\hline & Postgraduate & 17.8 & 178 \\
\hline \multirow{3}{*}{ Caregiver } & Parent(s) & 75.9 & 789 \\
\hline & Staying alone & 1.6 & 17 \\
\hline & Other & 22.5 & 234 \\
\hline \multirow{3}{*}{ Parent/Guardian Marital Status } & Married/Cohabiting & 58.5 & 576 \\
\hline & Single/Divorced & 33.2 & 327 \\
\hline & Widow/Widower & 8.3 & 82 \\
\hline \multirow{3}{*}{ Household Income Status* } & Low Income & 34.9 & 356 \\
\hline & Middle Income & 61.4 & 627 \\
\hline & High Income & 3.7 & 38 \\
\hline \multirow{2}{*}{ Parent/Guardian Work Status } & Employed & 65.4 & 552 \\
\hline & Unemployed & 34.6 & 292 \\
\hline
\end{tabular}

"= Lower income: Less than RI00 000; Middle income: RI00 000 - R300 000; Upper income: More than R300 000

Table 2 shows the results for the bivariate (Column 2) and multivariate (Column 3 ) respectively for ever had sex (lifetime sex). Amongst the variables in the equation, gender, grade, having a girlfriend/boyfriend, peer influence, religiosity, perception about sex issues, alcohol and drug use are found to be statistically significant in predicting lifetime sex in the sample. Specifically, Table 2 shows that males are more likely than their female counterparts to have ever had sex. For example, $47 \%$ of adolescent males report lifetime sex compared to only $23 \%$ of females.

This bivariate relationship is confirmed by the logistic regression analysis in column 3 which shows that the odds of males having lifetime sex are I.8 times higher than the odds of females having lifetime sex. Having a boyfriend or girlfriend increases the odds of lifetime sex. This finding is illustrated by the fact that the odds of adolescents who report having either a girlfriend or boyfriend are about 9 times higher than the odds of their counterparts who do not have a girlfriend or boyfriend having lifetime sex (Column 3).
Adolescents who have strong ties to their peers are more likely than those with weak ties to their peers to report lifetime sex. As the table shows, the bivariate relationship is confirmed by the multivariate analysis which shows that the odds of adolescents with strong peer ties are about 4 times higher than those of their counterparts who report weak ties to their peers.

Almost all religious organisations prohibit antisocial behaviours such as early initiation of sexual activities and sex outside of marriage. This is confirmed by the effect of religiosity on lifetime sex whereby adolescents who report strong religiosity are less likely than their counterparts who report weak religiosity to report lifetime sex. The odds of adolescents who report strong religiosity are 54\% less than those who report weak religiosity as illustrated by the multivariate analysis in column 3 .

Finally, the use of alcoholic beverages, tobacco and drugs such as marijuana are all positively associated with lifetime sex by adolescents. The odds of adolescents who have ever smoked cigarette having lifetime sex are more than 3 times 
higher than those of adolescents who have never smoked a cigarette.

Also, the use of alcoholic beverages increases an adolescent's chances of lifetime sex. Both the bivariate the multivariate analyses in columns 2 and 3 confirm this association. The odds of adolescents who have ever drunk alcohol are 2.64 times higher than those of adolescents who have never drunk. Finally, adolescents who report lifetime marijuana use also report lifetime sex; the odds of those who use marijuana having lifetime sex are 2.42 times higher than those who do not use this substance.

\section{TABLE 2: BIVARIATE AND MULTIVARIATE ANALYSES OF EVER HAD SEX}

\section{VARIABLES}

EVER HAD SEX

\section{LOGISTIC RESULTS}

(EXP B)

\begin{tabular}{llll}
\hline Gender & & & \\
& Male & 46.7 & $1.86 * *$ \\
\multicolumn{2}{c}{ Female (ref) } & 22.8 & 1.00 \\
\hline \multirow{2}{*}{ Grade } & & & \\
& $9^{\text {th }}($ ref $)$ & 18.5 & 1.00 \\
& $1^{\text {th }}$ & 44.5 & $4.90 * * *$ \\
\hline
\end{tabular}

Do you have a girlfriend/boyfriend?

$\begin{array}{ll}52.2 & 8.69 * * * \\ 9.2 & 1.00\end{array}$

\section{Peer Influence}

$\begin{array}{lll}\text { Weak (ref) } & 27.9 & 1.00 \\ \text { Strong } & 65.3 & 3.62 * * *\end{array}$

Religiosity

$\begin{array}{lll}\text { Weak (ref) } & 41.5 & 1.00 \\ \text { Strong } & 24.9 & 0.54^{* *}\end{array}$

Perception about Sex Issues

$\begin{array}{lll}\text { Unrealistic } & 40.4 & 1.80^{* *} \\ \text { Realistic (ref) } & 23.6 & 1.00\end{array}$

\section{Cigarette Smoking}

$\begin{array}{lll}\text { Never Smoked (ref) } & 28.3 & 1.00 \\ \text { Ever Smoked } & 66.9 & 3.07 \text { **** }\end{array}$

\begin{tabular}{lll}
\hline $\begin{array}{l}\text { Alcohol Drinking } \\
\text { Never Drunk (ref) }\end{array}$ & 21.3 & 1.00 \\
Ever Drunk & 53.7 & $2.64 * *$ \\
Marijuana use & & \\
Never used (ref) & 30.3 & 1.00 \\
Ever used & 68.9 & $2.42 *$
\end{tabular}




\begin{tabular}{lcc}
\hline Constant & $0.01 * * *$ \\
\hline Number of Cases Model & \\
\hline $\begin{array}{l}\text { Total Sample: } \\
\text { Proportion ever had sex: }\end{array}$ & 1051 & 956 \\
\hline
\end{tabular}

$$
* * * \mathrm{P}<0.001 ; * * \mathrm{P}<0.01 ; * \mathrm{P}<0.05
$$

Table 3 shows the results of the bivariate and multivariate analyses for recent sexual activity respectively. Like lifetime sex, recent sexual activity are influenced by a combination of selected individual and contextual factors such as gender, grade, parent-child relationship, school, peer, religiosity, having a girl/boyfriend and perception of sex issues. Males are more likely to report recent sexual activity than females. After controlling for all the other factors in the model, this bivariate relationship persists as shown in column 3 of the table; the odds of males reporting recent sexual encounter are 1.77 times higher than those of their female counterparts. Grade I I pupils are more than four times likely to report recent sexual encounter compared to their counterparts in Grade 9.

When parental value of children is low, adolescents are likely to engage in anti-social activities and vice versa. For instance, the odds of adolescent who report low parental value of children reporting recent sexual activity are I.32 times higher than the odds of adolescents who report high parental value reporting this behaviour. Similarly, when attachment to school is strong, adolescents are less likely to report recent sexual encounter; the odds of adolescents who report weak or loose attachment to school having multiple sexual partners are I.55 times higher than those of adolescents who report having multiple sexual partners.

Like lifetime sex, when ties to peers are strong, adolescents are likely to report recent sexual encounter. For example, the odds of those who report strong peer influence are 2.57 times higher than those of adolescents who report weak peer influence. Adolescents who report high religiosity are less likely to report recent sexual activity; the odds of reporting recent sexual encounter are decreased by $66 \%$ when adolescents report strong religiosity.

Again, the use of alcoholic beverages and drugs are positively associated with recent sexual encounter by adolescents. Specifically on tobacco use, adolescents who report ever use of tobacco are more likely than their counterparts who have never used the substance to report sexual activity in the three months preceding the survey. The odds of those who have ever smoked cigarette are almost 2 times (1.98) times higher than the odds of those who have never smoked cigarette. The same positive association between substance use and recent sexual encounter is observed for the use of alcohol and marijuana, whereby the odds of those who use these two substances are 2.42 and 2.23 times higher than those of adolescents who do not use these two substances.

TABLE 3: BIVARIATE AND MULTIVARIATE ANALYSES OF SEXUAL ENCOUNTERS IN THE 3 PAST MONTHS

VARIABLES

SEXUAL ENCOUNTERS IN THE 3 PAST LOGISTIC RESULTS
MONTHS

(EXP B)

Gender

$\begin{array}{lll}\text { Male } & 41.2 & 1.77^{*} \\ \text { Female (ref) } & 20.0 & 1.00\end{array}$


TABLE 3: CONTINUE

VARIABLES

SEXUAL ENCOUNTERS IN THE 3 PAST LOGISTIC RESULTS MONTHS

(EXP B)

\begin{tabular}{|c|c|c|}
\hline \multicolumn{3}{|l|}{ Grade } \\
\hline $9^{\text {th }}$ (ref) & 16.3 & 1.00 \\
\hline $1 \mathrm{I}^{\text {th }}$ & 39.0 & $4.92 * * * *$ \\
\hline \multicolumn{3}{|l|}{ School Attachment } \\
\hline Strong (ref) & 27.3 & 1.00 \\
\hline Loose & 38.4 & I.55* \\
\hline \multicolumn{3}{|l|}{ Do you have a girlfriend/boyfriend? } \\
\hline Yes & 46.9 & $9.80 * *$ \\
\hline No (ref) & 6.7 & 1.0 \\
\hline \multicolumn{3}{|l|}{ Peer Influence } \\
\hline Weak (ref) & 25.1 & 1.00 \\
\hline Strong & 54.4 & $2.57 * *$ \\
\hline \multicolumn{3}{|l|}{ Religiosity } \\
\hline Weak (ref) & 36.0 & 1.00 \\
\hline Strong & 22.5 & $0.66 *$ \\
\hline \multicolumn{3}{|l|}{ Perception about Sex Issues } \\
\hline Unrealistic & 20.0 & 1.00 \\
\hline Realistic (ref) & 36.0 & NS \\
\hline \multicolumn{3}{|l|}{ Cigarette Smoking } \\
\hline Never Smoked (ref) & 24.9 & 1.00 \\
\hline Ever Smoked & 59.0 & 1.98* \\
\hline \multicolumn{3}{|l|}{ Alcohol Drinking } \\
\hline Never Drunk (ref) & 18.8 & 1.00 \\
\hline Ever Drunk & 47.2 & $2.42 * * * *$ \\
\hline \multicolumn{3}{|l|}{ Marijuana use } \\
\hline Never used (ref) & 26.6 & 1.00 \\
\hline Ever used & 61.1 & $2.23 *$ \\
\hline $\begin{array}{l}\text { Total: } \\
\text { Constant }\end{array}$ & & $\begin{array}{l}29.9 \\
0.01 * * * * 1\end{array}$ \\
\hline Number of Cases Included in the Model & & 929 \\
\hline
\end{tabular}

$$
\text { *** } \mathrm{P}<0.001 ; * * \mathrm{P}<0.01 ;{ }^{*} \mathrm{P}<0.05
$$

Table 4 shows the results of the bivariate and logistic regression results for involvement with multiple sexual partners by adolescents. In terms of gender, males are much more likely than females to report involvement with multiple sexual partners, while grade II pupils are more likely than grade 9 pupils to report involvement with multiple sexual partners. Again, when parental value of children is low, adolescents are more likely to report this kind of sexual behaviour than when parental value of 
children is high. Involvement with a girlfriend or boyfriend is associated with involvement with multiple sexual partners, while low school attachment is similarly predictive of this sexual behaviour. Similarly, strong peer influence or ties is associated with involvement with multiple sexual partners as the odds of adolescents who report strong peer influence are 1.47 times higher than those of adolescents who report weak peer influence.

TABLE 4: BIVARIATE AND MULTIVARIATE ANALYSES OF LIFETIME MULTIPLE SEXUAL PARTNERS

VARIABLES

LOGISTIC RESULTS

\section{PARTNERS}

EXP B

\begin{tabular}{|c|c|c|}
\hline \multicolumn{3}{|l|}{ Gender } \\
\hline Male & 33.6 & $2.44 * * * *$ \\
\hline Female (ref) & 8.3 & 1.00 \\
\hline \multicolumn{3}{|l|}{ Grade } \\
\hline $9^{\text {th }}(\mathrm{ref})$ & 10.6 & 1.00 \\
\hline $1 I^{\text {th }}$ & 26.5 & $1.93 * * * *$ \\
\hline \multicolumn{3}{|c|}{ Parental Value of Children } \\
\hline Low & 30.6 & $1.37 * * * *$ \\
\hline High (ref) & 14.8 & 1.00 \\
\hline \multicolumn{3}{|l|}{ School Attachment } \\
\hline Strong (ref) & 28.5 & 1.00 \\
\hline Loose & 17.0 & $1.33 * * * *$ \\
\hline \multicolumn{3}{|c|}{ Do you have a girlfriend? } \\
\hline Yes & 30.7 & $3.22 * * * *$ \\
\hline No (ref) & 5.8 & 1.00 \\
\hline
\end{tabular}

\section{Peer Influence}

$\begin{array}{lll}\text { Weak (ref) } & 16.1 & 1.00 \\ \text { Strong } & 40.9 & 1.47 * * *\end{array}$

Religiosity

$\begin{array}{lll}\text { Weak (ref) } & 25.6 & 1.00 \\ \text { Strong } & 13.4 & 0.65 * * *\end{array}$

Perception about Sex Issues

$\begin{array}{lll}\text { Unrealistic } & 25.0 & 1.00 \\ \text { Realistic (ref) } & 12.4 & 1.20 *\end{array}$

Exposure to Sexual Content Media

Little (ref) 
TABLE 4: CONTINUE

$\begin{array}{ccc}\text { VARIABLES } & \text { MORE THAN } 2 \text { LIFE TIME SEXUAL } \\ \text { PARTNERS } \\ \text { EXP B }\end{array}$

\begin{tabular}{|c|c|c|}
\hline \multicolumn{3}{|l|}{ Cigarette Smoking } \\
\hline Never Smoked (ref) & 14.1 & 1.00 \\
\hline Ever Smoked & 54.7 & I. $5 \mathrm{I}$ ***** \\
\hline \multicolumn{3}{|l|}{ Alcohol Drinking } \\
\hline Never Drunk (ref) & 10.0 & 1.00 \\
\hline Ever Drunk & 35.5 & $1.60 * * *$ \\
\hline $\begin{array}{l}\text { Total: } \\
\text { Constant }\end{array}$ & & $\begin{array}{l}21.1 \\
0.09 * * * *\end{array}$ \\
\hline Number of Cases Included in the Model & & 844 \\
\hline
\end{tabular}

Note: -------- not included in the analysis for having statistically insignificant effect ***P $<0.001$; ** $\mathrm{P}<0.01$; $* \mathrm{P}<0.05$

\section{Conclusion}

While the literature on the effect of individuallevel factors on adolescent sexual behaviours in South Africa is proliferating, relatively very little is known about the effects of such contextual factors as the family, peers and school. The present study sought to fill this void in the existing literature by examining the effect of selected individual and contextual factors on adolescent risk-taking behaviours in a poor district in the North West Province of South Africa.

The findings of the study corroborate existing empirical evidence that adolescent development in general, and adolescent anti-social behaviours in particular, are affected by both personal characteristics and such broad societal conditions as family, school and peer influences. At the individual level, we observe that males and adolescents in grade II are much more likely than females to report such risky sexual behaviours as lifetime sexual activity, recent sexual activity and involvement with multiple sexual partners than their female and grade 9 counterparts respectively. At the level of the contextual factors, we observe that the family, in the form of parental values of children, school attachment, peer influence, the media and religion all affect adolescent development.

In conclusion, the present study has drawn attention to the individual and structural factors that might help us to predict adolescent sexual risk behaviours as opposed to the bulk of the existing studies in South Africa that focus mainly on the incidence of such behaviours. With regards to the contextual factors of family and peer influences, the study has essentially shown that the family is a multidimensional construct which affects adolescent problem behaviours in different ways. The parentchild relationship, especially, parent-child communication is very important in engendering pro-social behaviours in the adolescent child so parenting as far as the adolescent child is concerned must seek to demonstrate how much parents value them vis a vis the adolescent's peers and other social contexts besides the family.

\section{References}

Amoateng, A.Y. and Kalule-Sabiti, I. 2013. Social Structure and Sexual Behaviour of Black

African Adolescents in the North West Province, South Africa. South African Review of Sociology, 44 (I): 131-157.

Department of Education and Culture, KwazuluNatal. 2000. 'Integrated plan for children affected and infected with HIV and AIDS'. Business plan for lifeskills. HIV and AIDS Education: Secondary schools phase. April 2000-March 2001

Department of Health, Medical Research Council \& OrcMacro 2007 South Africa

Demographic and Health Survey 2003. Pretoria: Department of Health.

Flisher, A.J., Reddy, P., Muller, M. and Lombard, C. 2003. 'Sexual Behaviour of

Cape Town High-School Students'. South African Medical Journal, 93, pp 537-54I.

Flisher A.J., Parry C.D,, Evans J.et al. 2003. 'Substance use by adolescents in Cape Town: 
prevalence and correlates'. Journal of Adolescent Health, 32(I), pp 58-65.

Flisher A.J., Ziervogel C.F., Chalton D.O. et al. 1996. Risk-taking behaviour of Cape Peninsula high-school students: Part IX. Evidence for a syndrome of adolescent risk behaviour. South African Medical Journal, 86: 1090 -3.

Flisher A.J., Chalton D.O. 200I. Adolescent contraceptive non-use and covariation among risk behaviours. Journal of Adolescent Health, 28:235-4I.

Garner, C. R. 2000. Safe Sects? Dynamics Religion and Aids in South Africa.

Journal of Modern African Studies, 38 (I): 4I-69.

Gillmore, M.R., Archibald, M.E., Morrison, D.M., Wilsdon, A., Wells, E.A., Hoppe,

M.J., Nahom, D. and Murowchick, E. 2002. 'Teen sexual behaviour: applicability of the theory of reasoned action'. Journal of Marriage and the Family, 64(4), pp. 885-897.

Hardy, S.A. and Raffaelli, M. 2003. 'Adolescent Religiosity and Sexuality: An Investigation of Reciprocal Influences'. Journal of Adolescence, 26(6), pp. 73I-739

Kaaya, S.F., Flisher, A.J., Mbwambo, J.K., Schaalma, H., Aaro, L.E. and Klepp, K.I.2002.

'A Review of Studies of Sexual Behaviour of School Students in sub-Saharan Africa'. Scandinavian Journal of Public Health, 30, pp. I48-160.

Karim, A.M., Magnani, R.J., Morgan, G.T., and Bond, K.C.2003. Reproductive Health

Risk and Protective Factors among Unmarried Youth in Ghana. International Family Planning Perspectives, Vol. 29, No. I, March, I4-24.

Khan, M.A.2002. 'Knowledge on AIDS among female adolescents in

Bangladesh: Evidence from the Bangladesh Demographic and Health Survey Data'. Journal of Health, Population and Nutrition, 20(2), pp I307.

Kinsman, S.B., Romer, D., Furstenberg, F.F., and Schwarz, D. 1998.

'Early Sexual Initiation: The Role of Peer Norms'. Pediatrics, 102(5), pp II85-1 I 92

Kwankye, S.O. 2005. 'Female Adolescents and Reproductive Change in Ghana: Evidence from an Adolescent Survey of two Communities'. African Population Studies, 21, pp. I I9-150.

Lammers, S., Ireland, M., Resnick, M., and Blum, R. 2000. Influences on adolescents' decision to postpone onset on sexual intercourse: A survival analysis of virginity among youth aged 13- 18 years. Journal of Adolescents Health, 26(I): 4248

Lowry R, Holtzman D., Truman B.I. et al. 1994. Substance use and HIV-related sexual behaviours among US high school students: are they related? American Journal of Public Health, 84: I I 16 -20.

McGrath, N, Nyirenda, M, Hosegood, V. and Newel, M.L. 2009. Age at first sex in rural

South Africa. Sexually Transmitted Infections, 85(Suppl (I):i49-i55.

McMillen, E. K, Helm, H.W and McBridge, D.C. 20II. Religious Orientation and Sexual

Attitudes and Behaviours, Journal of Research on Christian Education, Andrews University, 20 (I): 195-206.

Nahom, D., Wells, E., Gillmore, M.R., Hoppe, M., Morrison, D.M., Archibald, M.

Murowhick, E., Wilsdon, A., and Graham, L. 200I. 'Differences by gender and sexual experience in adolescent sexual behaviour: Implications for educations and HIV prevention'. Journal of School Health, 7I: 143-I64.

Nikula, M. 2009. Young men's sexual behaviour in Finland and Estonia: Opportunities for prevention of STI. Finland: National Institute of Health and Welfare and Department of Public Health University of Helsinki.

Ntozi, J.P.M., Ahimbisibwe, F.E., Ayiga, N., Odwee, J., and Mulindwa, I.N. 2000.

'Has AIDS awareness changed sexual behaviour in Uganda?' in J. C. Caldwell, P. Caldwell, I.O. Orubuloye, J.P.M. Ntozi, K. Awusabo-Asare, J. Anarfi, B. Caldwell, C. Varga, J. Malungo, B.Missingham, W. Cosford and E. Hollings (eds) Towards Containment of the AIDS Epidemic: Social and Behavioural Research. Canberra, Australia: Health Transition Centre, the Australian National University, pp. 63-78.

Odimegwu, C. 2005. Influence of Religion on Adolescent Sexual Attitudes and Behaviour among Nigerian University Students: Affiliation or Commitments? Women's Health and Action Research Centre, 9 (2): I25- 140.

Palen, L, Smith, E.A., Flisher, A.J., Caldwell, L.L., and Mpofu, E. 2006. Substance Use and Sexual Risk Behaviour among South African Eighth Grade Students. Journal of Adolescent Health, 39: 76I763. 
Panday, S., Reddy, S.P., Ruiter, R.A.C., Bergstrom, E., De Vries, H. 2007.

'Determinants of smoking among adolescents in the Southern Cape-Karoo region, South Africa'. Health Promotion International, 22, pp 207-2I 7.

Peltzer, K. 2003. 'HIV/AIDS/STD knowledge, attitudes, beliefs and behaviours in a rural

South African adult population'. South African Journal of Psychology, 33(4), pp 250-260.

Rostosky, S.S., Regnerus, M.D. and Comer Wright, M.L. 2003.

'Coital Debut: The Role of Religiosity and Sex Attitudes in the Add Health Survey'. Journal of Sex Research, 40(4): 358-367

Shisana, O. and Simbayi, L. 2003. Nelson Mandela/HSRC Study of HIV/AIDS: South

African National HIV Prevalence, Behavioural Risks and Mass Media; Household Survey 2002. Cape Town: Human Sciences Research Council.

Simbayi, L.C., Mwaba, K., \& Kalichman, S. 2006. Perceptions of STI clinic attenders about HIV/AIDS and alcohol as a risk factor with regard to HIV infection in South Africa: Implications for HIV prevention. Social Behaviour and Personality, 34: 535-544.

Tapert S.F., Aarons G.A., Sedlar G.R., et al. $200 \mathrm{I}$. Adolescent substance use and sexual risk-taking behaviour. Journal of Adolescent Health, 28:18I9.

Taylor, C.C. 1990. 'Condoms and Cosmology: The 'Fractal' Person and Sexual Risk in

Rwanda'. Social Science and Medicine, 3I, pp 1023 1028.

Upchurch, D.M., Aneshensel, C.S., Sucoff, C.A., and Levi-Storms, L. 1999.

'Neighborhood and Family Contexts of Adolescent Sexual Activity'. Journal of Marriage and the Family, 6I, pp. 920-933

Whitaker, D.J. and Miller, K.S. 2000. 'ParentAdolescent Discussions about Sex and

Condoms: Impact on Peer Influences of Sexual Risk Behaviours'. Journal of Adolescent Research, I5(2): 25 I-273 